\title{
The time-varying effect of inflation uncertainty on inflation for Turkey
}

\section{Serdar Varlik, Volkan Ulke \& Hakan Berument}

To cite this article: Serdar Varlik, Volkan Ulke \& Hakan Berument (2017) The time-varying effect of inflation uncertainty on inflation for Turkey, Applied Economics Letters, 24:13, 961-967, DOI: 10.1080/13504851.2016.1243206

To link to this article: https://doi.org/10.1080/13504851.2016.1243206

View supplementary material $\circlearrowright$

曲 Published online: 14 Oct 2016.

Submit your article to this journal

山 Article views: 188

Q View related articles $\widetilde{ }$

View Crossmark data \lceil 


\title{
The time-varying effect of inflation uncertainty on inflation for Turkey
}

\author{
Serdar Varlik ${ }^{\mathrm{a}}$, Volkan Ulke ${ }^{\mathrm{b}}$ and Hakan Berument ${ }^{\mathrm{c}}$ \\ aDepartment of Economics, Hitit University, Corum, Turkey; ${ }^{b}$ Faculty of Economics and Social Sciences, International Burch University, \\ Sarajevo, Bosnia and Herzegovina; 'Department of Economics, Bilkent University, Ankara, Turkey
}

ABSTRACT

We investigate the effect of inflation uncertainty on inflation from January 1982 through March 2016 for Turkey by using the Stochastic Volatility in Mean model with time-varying parameters. Our empirical evidence from consumer price index (CPI) inflation suggests that the observed positive relationship between inflation and inflation uncertainty is not robust. This positive relationship diminishes after 2002. This finding is valid for all five subcomponents of CPI inflation; however, for Health Services, Transportation Services, and Recreational and Cultural Services, an inflation-positive association is reported after 2010.

\section{KEYWORDS}

Inflation; inflation uncertainty and TVP-SVM

JEL CLASSIFICATIONS E31; C11; C15; C22

\section{Introduction}

The economic costs of both inflation and inflation uncertainty are well documented in the literature, and thus, the relationship between these two variables is a heavily investigated issue. Cukierman and Meltzer (1986) suggest that inflation uncertainty increases inflation because inflation uncertainty encourages central banks to create surprise inflation by stimulating output growth over potential output via monetary expansion. However, Holland (1995) argues that inflation uncertainty decreases inflation because in high inflation periods, central banks are willing to decrease inflation uncertainty to reduce the welfare costs of tight monetary policy. On the relationship between inflation and inflation uncertainty, the current article provides empirical evidence from one of the few countries that has experienced high persistent inflation for more than four decades across different commodity groups: Turkey.

There are several methods by which to measure the relationship between inflation and inflation uncertainty. Autoregressive Conditional Heteroscedasticity in the Mean (ARCH-M) class of models, Stochastic Volatility in the Mean (SVM) models and Kalman Filter models are the most common ones. ARCH-M models take the conditional variance of inflation as a measure of inflation uncertainty with a set of pre-determined variables. ${ }^{1}$ The SVM model proposed by Koopman and Hol Uspensky (2002) is another alternative; in SVM models volatility changes stochastically and variance is a random variable. ${ }^{2}$ The Kalman Filter method allows us to observe the parameters of the inflation equation as time varying and takes its volatility as a measure of uncertainty parameters. ${ }^{3}$ Chan (2015) extends SVM models with time-varying parameters (TVP) for the relationship between inflation and inflation uncertainty in the conditional mean. This method is called the TVP-SVM model, and it is superior to the others because of its observations of the structural changes in parameters over time on the relationship between inflation and inflation uncertainty.

In this article, we attempt to assess the effect of inflation uncertainty on inflation with an innovative stochastic volatility in the mean model with timevarying parameters (TVP-SVM) introduced by Chan (2015). We use Turkish data because it has advantages that other countries cannot provide: (i) prior to

\footnotetext{
CONTACT Hakan Berument berument@bilkent.edu.tr

${ }^{1}$ Various empirical studies for the inflation and inflation uncertainty relationship use ARCH-M models: Grier and Perry (1998), Apergis (2004), Fountas, loannidi, and Karanasos (2004), Conrad and Karanasos (2005), Berument and Dincer (2005). Nas and Perry (2000) and Erkam (2008) also find empirical evidence that inflation uncertainty affects inflation for Turkey.

${ }^{2}$ Berument, Yalcin, and Yildirim (2009) find empirical evidence that innovation in inflation uncertainty increases inflation.

${ }^{3}$ Evans (1991) and Berument, Kilinc, and Ozlale (2005) are examples of inflation uncertainty measures for the Kalman Filter method.

(1) Supplemental data for this article can be accessed here.

(c) 2016 Informa UK Limited, trading as Taylor \& Francis Group
} 
adopting an inflation-targeting regime in 2002, Turkey had high inflation and inflation volatility for more than three decades without running to hyperinflation (see Fig. 1 for inflation and Fig. 2 for uncertainty). Thus, there is a low chance of Type-II error. (ii) Turkey has a market economy, and for the period we consider Turkey did not freeze prices. (iii) Turkey had several structural and policy changes over the period that we consider: before 1999, the Central Bank of the Republic of Turkey (CBRT) used both exchange rate and interest rate as policy tools (see Berument 2007). Between December 1999 and February 2001, the CBRT used an exchange-rate-based monetary policy, and after March 2001, they used an interest-rate-based policy. (iv) In 2002, the CBRT adopted implicit inflation targeting and in 2006, it adopted explicit inflation targeting. (v) As of 2015, Turkey is the eighteenth largest economy in the world; this is itself important.
All prices in an economy have different characteristics, and can be affected by different economic variables at different degrees. For this reason, we examine subcomponents of CPI inflation as well as overall CPI inflation. To the best of our knowledge, our article is the first to observe inflation and inflation uncertainty for the subcomponents of CPI inflation. Different results across different sectors might show that the relationship between inflation and inflation uncertainty may not solely be due to a monetary policy stance but that the nature of the sector/commodity may also play a role. From the empirical evidence gathered in this article, (i) we suggest that there is a substantial decrease in the uncertainty of CPI inflation and its subcomponents after 2002, with the adoption of the (implicit) inflation-targeting regime; (ii) our estimation results indicate that there exists substantial time variation in the parameter for inflationinflation uncertainty before 2002; (iii) we observe (a) CPI Inflation Rate

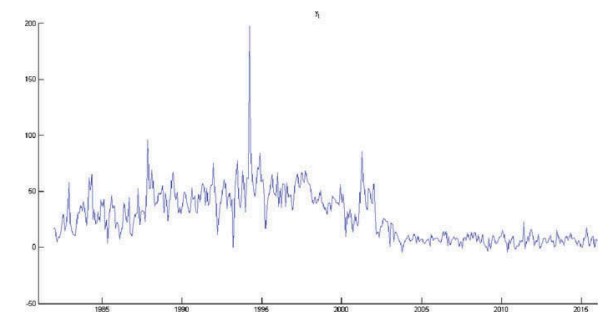

(c) Furnishings, Household Equipment, Routine Maintenance of House Inflation Rate

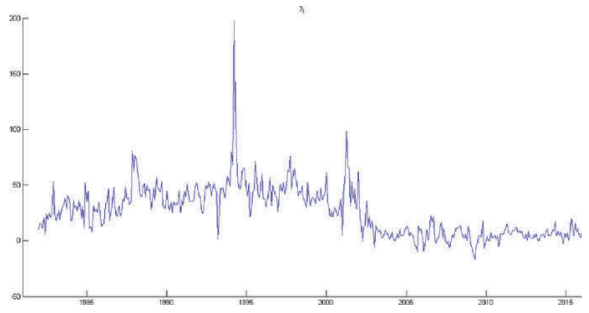

(e) Transportation Services Inflation Rate

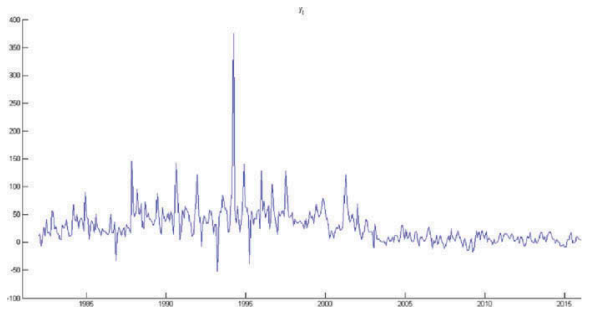

(b) Clothing and Footwear Inflation Rate

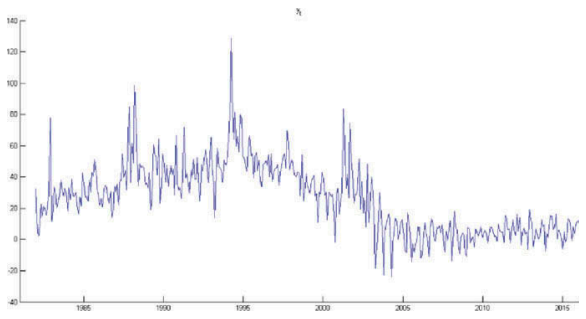

(d) Health Services Inflation Rate

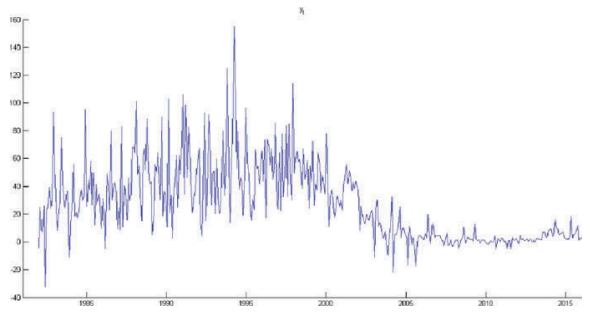

(f) Recreational and Cultural Services Inflation Rate

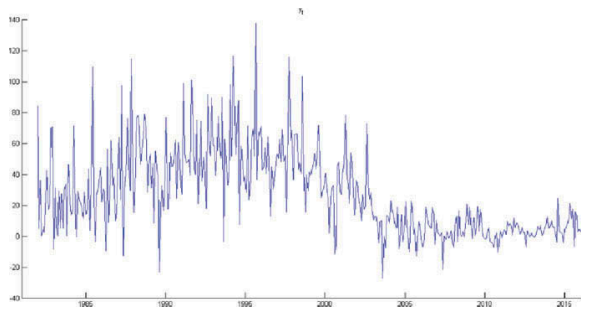

Figure 1. Monthly CPI inflation and its subcomponents for the period from 1982M01 to $2016 \mathrm{M} 03$ in Turkey. (a) CPI inflation rate; (b) clothing and footwear inflation rate; (c) furnishings, household equipment, routine maintenance of house inflation rate; (d) health services inflation rate; (e) transportation services inflation rate; (f) recreational and cultural services inflation rate. 
(a) CPI Inflation Rate

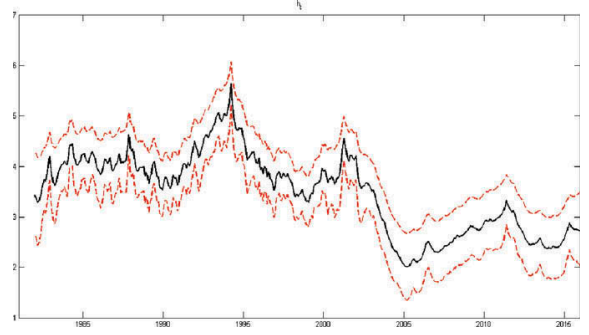

(c) Furnishings, Household Equipment, Routine Maintenance of House Inflation Rate

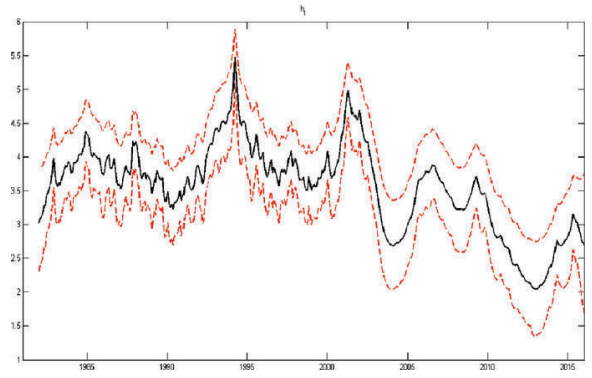

(e) Transportation Services Inflation Rate

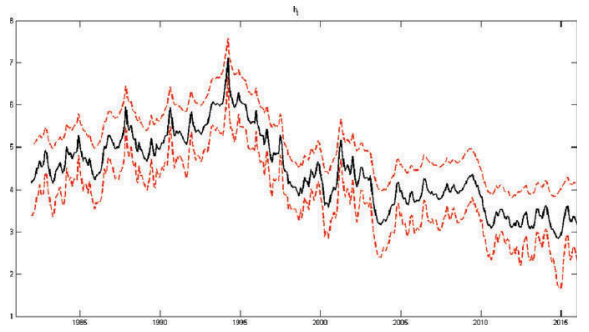

(b) Clothing and Footwear Inflation Rate

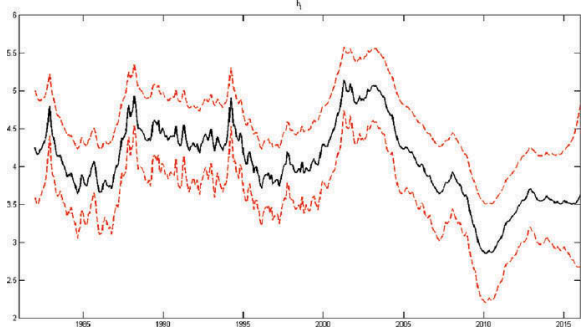

(d) Health Services Inflation Rate

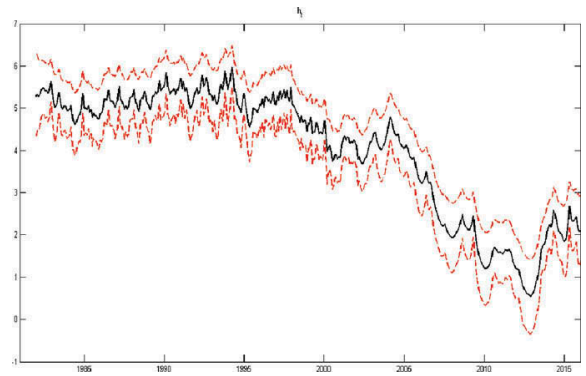

(f) Recreational and Cultural Services Inflation Rate

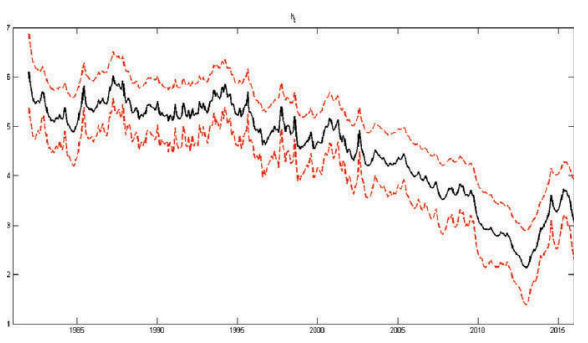

Figure 2. Volatility of monthly CPI Inflation and its subcomponents $\left(h_{t}\right)$. (a) CPI inflation rate; (b) clothing and footwear inflation rate; (c) furnishings, household equipment, routine maintenance of house inflation rate; (d) health services inflation rate; (e) transportation services inflation rate; (f) recreational and cultural services inflation rate. The solid lines are the estimated posterior means and the dashed lines are the $90 \%$ confidence bands.

both positive and ambiguous effects of inflation uncertainty on inflation for CPI inflation and a cross sector after the inflation-targeting period; (iv) the previous result indicates that the implementations of a financial-stability-oriented monetary policy under the new monetary policy framework since November 2010 increase the effect of inflation uncertainty on inflation and (v) we observe that after 2010 the impact of inflation uncertainty on inflation has a statistically significant positive association for Health Services, Transportation Services and Recreational and Cultural Services.

This article is organized as follows: In Section II, we describe the data sets. In Section III, we outline the TVP-SVM methodology employed by Chan (2015). Section IV presents the empirical evidence. Section V concludes the paper.

\section{Data}

In order to investigate the inflation-inflation uncertainty relationship, we use the monthly consumer price index (CPI) data and its five subcomponents for the period January 1982 to March 2016 from Turkey. The subcomponents are: (i) Clothing and Footwear, (ii) Furnishings, Household Equipment and Routine Maintenance of House, (iii) Health Services, (iv) Transportation Services and (v) Recreational and Cultural Services, and with these we evaluate the time-varying effect of inflation uncertainty on inflation. We gather data from the CBRT's Electronic Data Delivery System (EDDS). The TVP-SVM model is highly nonlinear; thus to avoid the local maximum problem, we decrease the number of parameters to be estimated. Therefore, we 
use seasonal adjusted series rather than seasonal dummies to account for seasonality. To account for seasonality, we apply the Census X-12 method to the series. The monthly inflation series are calculated as

$\pi_{t}=\frac{P_{t}-P_{t-1}}{P_{t-1}} \times 100$, where $P_{t}$ is the level of the price index in month $t$. The Appendix provides the definitions and sources of the variables.

\section{Methodology}

We adopt the TVP-SVM model to assess how the effect of inflation uncertainty on inflation changes over time. We employ a model that extends Koopman and Uspensky's (2002) SVM model by allowing time parameters to be time varying (Chan 2015).

The structure of the SVM model can be represented as follows:

$$
\begin{gathered}
y_{t}=x_{t}^{\prime} \beta_{t}+\alpha_{t} e^{h_{t}}+\varepsilon_{t}^{y} \quad \varepsilon_{t}^{y} \sim \mathcal{N}\left(0, e^{h_{t}}\right) \\
h_{t}=\mu+\phi\left(h_{t-1}-\mu\right)+\varepsilon_{t}^{h} \quad \varepsilon_{t}^{h} \sim \mathcal{N}\left(0, \sigma^{2}\right)
\end{gathered}
$$

Here, $y_{t}$ is the time series of interest. $x_{t}$ is the $k \times$ 1 vector of a set of explanatory variables. $\beta_{t}$ is a $k \times 1$ vector of time-varying parameters. $\varepsilon_{t}^{y}$ and $\varepsilon_{t}^{h}$ are disturbances that are mutually and serially uncorrelated. The logarithmic volatility $h_{t}$ is assumed to follow a stationary $\operatorname{AR}(1)$ process with $|\phi|<1$. Also, $h_{t}$ is initialized with $h_{1} \sim \mathcal{N}\left(\mu, \frac{\sigma^{2}}{1-\phi^{2}}\right)$.

As $\alpha_{t}$ and $\beta_{t}$ are time-varying parameters, the vector of coefficients $\gamma_{t}=\left(\alpha_{t}, \beta_{t}^{\prime}\right)^{\prime}$ evolves as a first-order random walk process:

$$
\gamma_{t}=\gamma_{t-1}+\varepsilon_{t}^{\gamma} \quad \varepsilon_{t}^{\gamma} \sim \mathcal{N}(0, \Omega)
$$

The random walk process is initialized with $\gamma_{1} \sim \mathcal{N}\left(\gamma_{0}, \Omega_{0}\right)$ for the constant matrices of $\gamma_{0}$ and $\Omega_{0} . \Omega$ is a $(k+1) \times(k+1)$ covariance matrix. The model is reduced to a standard TVP regression with stochastic volatility in Equations 1-3, as long as $\alpha_{t}=$ 0 for all $t=1, \ldots, T$. If $\alpha_{t} \neq 0$, the model allows the additional channel of persistence. Thus, any shock persisting from $h_{t-1}$ affects $h_{t}$ and in this way the conditional mean of $y_{t}$ is affected. ${ }^{4}$

Equations 1-3 define the Gaussian state-space model, which is linear in $\gamma_{t}$ and nonlinear in $h_{t}$.
When the model is nonlinear in $h_{t}$, the estimation is more difficult. The Maximum Likelihood (ML) method could not ensure reliable results for the parameters. When this is the case, Chan (2015) suggests using the efficient Markov Chain Monte Carlo (MCMC) algorithm method instead of the Kalman Filter method. In this way, each type of state can be individually stimulated.

Following that step, Chan (2015) suggests that to fulfil the model specification, it is assumed that the independent priors for $\sigma^{2}, \mu, \phi$ and $\boldsymbol{\Omega}$ are

$$
\begin{aligned}
& \mu \sim \mathcal{N}\left(\mu_{0}, V_{\mu}\right), \phi \sim \mathcal{N}\left(\phi_{0}, V_{\phi}\right) 1(|\phi|<1), \\
& \sigma^{2} \sim I \mathcal{G}\left(v_{\sigma^{2}}, S_{\sigma^{2}}\right), \boldsymbol{\Omega} \sim I \mathcal{W}\left(v_{\Omega}, \mathbf{S}_{\boldsymbol{\Omega}}\right)
\end{aligned}
$$

$I \mathcal{G}$ and $I \mathcal{W}$ indicate the inverse-Gamma and inverseWishart distributions. Also, following Chan (2015), we impose the stationary condition $|\phi|<1$ on the prior for $\phi$. In the framework of notational convenience, $x$ indicates the covariates, $\mathbf{y}=\left(y_{1}, \ldots, y_{T}\right)^{\prime}$, $\gamma=\left(\gamma_{1}^{\prime}, \ldots, \gamma_{T}^{\prime}\right)^{\prime}$ and $\mathbf{h}=\left(h_{1}, \ldots, h_{T}\right)^{\prime}$. In this case, we describe the posterior drawing process as follows:

$$
\begin{aligned}
& \text { - } p\left(\boldsymbol{h} \mid \boldsymbol{y}, \boldsymbol{x}, \boldsymbol{\gamma}, \mu, \phi, \sigma^{2}, \boldsymbol{\Omega}\right)=p\left(\boldsymbol{h} \mid \boldsymbol{y}, \boldsymbol{x}, \boldsymbol{\gamma}, \mu, \phi, \sigma^{2}\right) \\
& \text { - } p\left(\boldsymbol{y} \mid \boldsymbol{y}, \boldsymbol{x}, \boldsymbol{h}, \mu, \phi, \sigma^{2}, \boldsymbol{\Omega}\right)=p(\boldsymbol{y} \mid \boldsymbol{y}, \boldsymbol{x}, \boldsymbol{h}, \boldsymbol{\Omega}) \\
& \text { - } p\left(\boldsymbol{\Omega}, \sigma^{2} \mid \boldsymbol{y}, \boldsymbol{x}, \boldsymbol{\gamma}, \boldsymbol{h}, \mu, \phi\right)=p(\boldsymbol{\Omega} \mid \boldsymbol{y}) p\left(\sigma^{2} \mid \boldsymbol{h}, \mu, \phi\right) \\
& \text { - } p\left(\mu, \phi \mid \boldsymbol{y}, \boldsymbol{x}, \boldsymbol{\gamma}, \boldsymbol{h}, \sigma^{2}, \boldsymbol{\Omega}\right)=p\left(\mu, \phi \mid \boldsymbol{h}, \sigma^{2}\right)
\end{aligned}
$$

To model inflation, Chan (2015) decomposes inflation into two unobserved components of trend and transitory, following Stock and Watson (2007). While the variance of the trend component is constant, the transitory component has a stochastic volatility. In this sense, it is assumed that inflation might be affected by its own volatility and that the volatility of current inflation might be affected by its past inflation experiences. This assumption reflects that inflation volatility originates from the conditional mean and the conditional variance. From this point of view, the model structure is explained in Equations (5-7).

$$
\begin{aligned}
y_{t}= & \tau_{t}+\alpha_{t} e^{h_{t}}+\varepsilon_{t}^{y} \quad \varepsilon_{t}^{y} \sim \mathcal{N}\left(0, e^{h_{t}}\right) \\
h_{t}= & \mu+\phi\left(h_{t-1}-\mu\right)+\beta y_{t-1} \\
& +\varepsilon_{t}^{h} \quad \varepsilon_{t}^{h} \sim \mathcal{N}\left(0, \sigma^{2}\right)
\end{aligned}
$$

\footnotetext{
${ }^{4}$ In order to grantee to have a finite mean for each inflation series, we perform the Augmented Dickey-Fuller and Phillips-Perron unit root tests (not reported to save space). The test statistics suggest that all the inflation series are I(0).
} 


$$
\gamma_{t}=\gamma_{t-1}+\varepsilon_{t}^{\gamma} \quad \varepsilon_{t}^{\gamma} \sim \mathcal{N}(0, \Omega)
$$

Here $y_{t}$ is inflation, $\gamma_{t}=\left(\alpha_{t}, \tau_{t}\right)^{\prime}$ and $\boldsymbol{\Omega}$ is a $2 \times 2$ covariance matrix. $\exp \left(h_{t}\right)$ is for the variance of the transitory component. $\alpha_{t}$, the time-varying coefficient in the conditional mean equations, measures the impact of transitory volatility on the level of inflation at time $t$. Also, past inflation $y_{t-1}$ is a covariate in the conditional variance equation. The coefficient of past inflation $\beta$ appears in the MCMC algorithm as an extra block. ${ }^{5}$

\section{Empirical evidence}

We estimate the TVP-SVM model to examine the effects of inflation uncertainty on inflation for Turkey. We draw 50000 samples after the initial 5000 samples are discarded in the burn-in period.

Figure 2 reports the log volatility of CPI inflation and its subcomponents $\left(h_{t}\right)$, the six of which have substantially higher inflation uncertainty prior to 2002. This finding reflects the high economic instability in the Turkish economy for the corresponding period. ${ }^{6}$ Notably, high CPI inflation volatility, peaking in 1994, exposes the effects of the April 1994 economic crisis. After the February 2001 economic crisis, a floating exchange rate regime was adopted in that month and in April 2001 Turkey announced its Transition to a Strong Economy Program. The CBRT later implemented an implicit inflation-targeting regime from January 2002 to December 2005. It seems that there is a significant downward trend in the volatilities of the CPI inflation rate and its subcomponents alongside the inflationtargeting regime. In January 2006, the CBRT adopted an explicit inflation-targeting regime, and since then, the volatilities of CPI inflation and Transportation Services inflation have begun to gradually increase. The reasons for soaring volatility might be attributed to the effects of external shocks on domestic prices, such as increasing raw material prices, the global financial crisis and euro zone financial turbulence. Furthermore, just after 2010, the volatilities of Clothing and Footwear, Health Services, and Recreational and Cultural Services inflation began an upward trend.
We capture the effects of inflation uncertainty on inflation for CPI inflation and the subcomponents of CPI inflation in Fig. 3. The estimates for the $\alpha_{t}$ parameter are time-variant for the whole period. When considering the $90 \%$ confidence intervals, the parameter is statistically different from zero from 1982 until late 2003. The effects of inflation uncertainty on inflation were generally high before 2002 for CPI inflation and its subcomponents. After Turkey's official adoption of an inflation-targeting regime, the effects decrease. Therefore, one can infer that an increase in the credibility of monetary policy decreases the effects of inflation uncertainty on inflation. On the other hand, the effect of inflation uncertainty on inflation differentiates for the subcomponents of CPI inflation along the inflation-targeting period. The relationship between inflation uncertainty and inflation is not statistically significant for CPI inflation, Clothing and Footwear, Furnishings, Household Equipment or Routine Maintenance of House after late 2003. However, after 2010, we find a statistically significant positive relationship between inflation uncertainty and inflation for Health Services, Transportation Services and Recreational and Cultural Services.

\section{Conclusion}

In this article, we use the Stochastic Volatility in the Mean model (SVM) with the Time Varying Parameters (TVP-SVM) model introduced by Chan (2015) to investigate the effects of inflation uncertainty on inflation over the January 1982 to March 2016 period for Turkey across different price indexes. Our gathered empirical evidence reveals that the relationship between inflation and inflation uncertainty is time-variant for CPI inflation and its subcomponents. The evidence from consumer price index (CPI) inflation suggests that the observed positive relationship between inflation and inflation uncertainty is not robust. This positive relationship diminishes after 2002. These results are valid for all five subcomponents of CPI inflation that we consider; however, for Health Services, Transportation Services, and Recreational and Cultural Services, an inflation-positive association is also found after 2010.

\footnotetext{
${ }^{5}$ For more information about the values of the hyper-parameters of independent priors for $\sigma^{2}, \mu, \phi, \Omega$ as described in Equation (4) of Chan (2015).

${ }^{6}$ This period can be characterized by a high public deficit, a high interest rate and economic crises, such as in April 1994 and from November 2000 to February 2001. Also, Turkey experienced effects of external crises such as the East Asian crises in July 1997 and the Russian crises in 1998.
} 
(a) CPI Inflation Rate

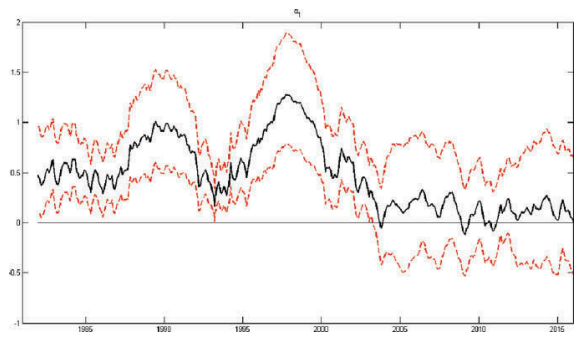

(c) Furnishings, Household Equipment, Routine Maintenance of House Inflation Rate

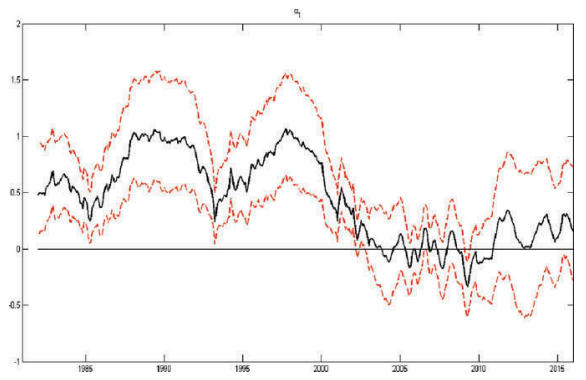

(e) Transportation Services Inflation Rate

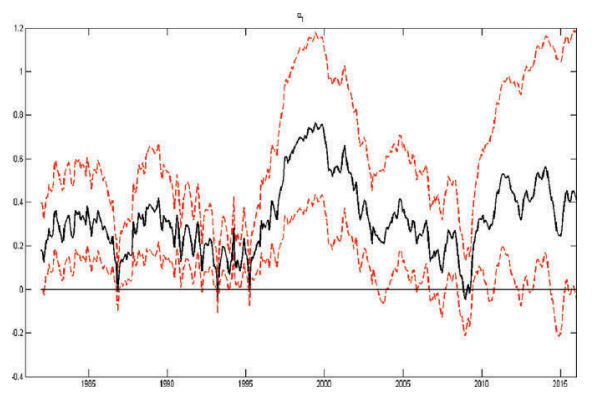

(b) Clothing and Footwear Inflation Rate

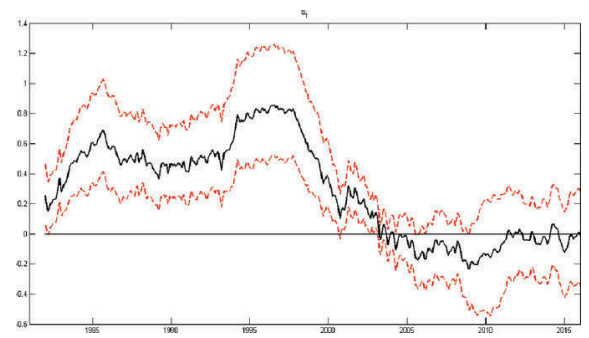

(d) Health Services Inflation Rate

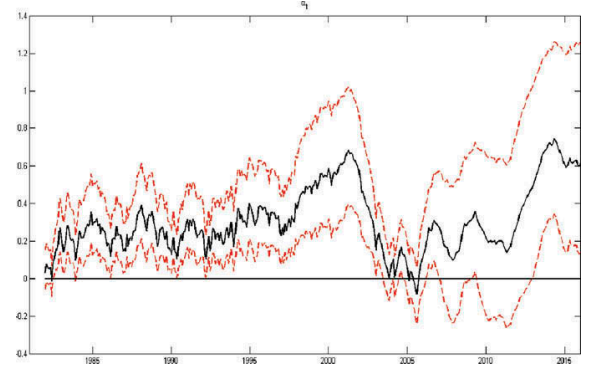

(f) Recreational and Cultural Services Inflation Rate

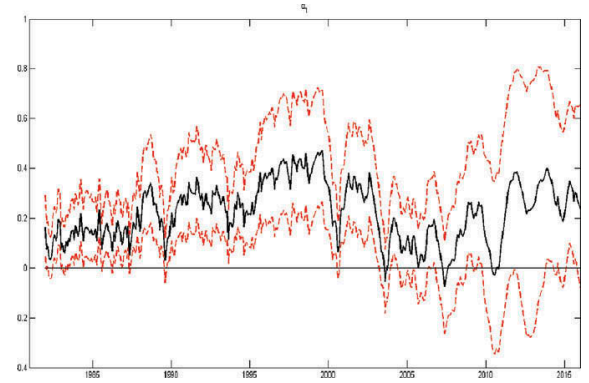

Figure 3. Impact of monthly CPI inflation on CPI inflation $\left(a_{t}\right)$. (a) CPI inflation rate; (b) clothing and footwear inflation rate (c) furnishings, household equipment, routine maintenance of house inflation rate (d) health services inflation rate (e) transportation services inflation rate $(f)$ recreational and cultural services inflation rate. The solid lines are the estimated posterior means and the dashed lines are the $90 \%$ confidence bands.

\section{Acknowledgement}

We would like to thank Rana Nelson for her helpful comments.

\section{Disclosure statement}

No potential conflict of interest was reported by the authors.

\section{References}

Apergis, N. 2004. "Inflation, Output Growth, Volatility and Causality: Evidence from Panel Data and the G7 Countries." Economics Letters 83 (2): 185-191. doi:10.1016/j.econlet.2003.11.006.

Berument, H. 2007. "Measuring Monetary Policy for A Small Open Economy: Turkey." Journal of Macroeconomics 29 (2): 411-430. doi:10.1016/j. jmacro.2006.02.001.
Berument, H., and N. N. Dincer. 2005. "Inflation and Inflation Uncertainty in the G7 Countries." Physica A: Statistical Mechanics and its Applications 348: 371-379. doi:10.1016/j.physa.2004.09.003.

Berument, H., Z. Kilinc, and U. Ozlale. 2005. "The Missing Link Between Inflation Uncertainty and Interest Rates." Scottish Journal of Political Economy 52 (2): 222-241. doi:10.1111/sjpe.2005.52.issue-2.

Berument, H., Y. Yalcin, and J. Yildirim. 2009. “The Effect of Inflation Uncertainty on Inflation: Stochastic Volatility in Mean Model within a Dynamic Framework." Economic Modelling 26 (6): 1201-1207. doi:10.1016/j.econmod.2009.05.007.

Chan, J. C. C. 2015. "The Stochastic Volatility in Mean Model with Time-Varying Parameters: An Application to Inflation Modeling." Journal of Business \& Economic Statistics, no. forthcoming. doi:10.1080/07350015.2015.1052459.

Conrad, C., and M. Karanasos. 2005. "On The InflationUncertainty Hypothesis in The USA, Japan and the UK: 
A Dual Long Memory Approach." Japan and the World Economy 17 (3): 327-343. doi:10.1016/j.japwor.2004.03.002.

Cukierman, A., and A. Meltzer. 1986. "A Theory of Ambiguity, Credibility, and Inflation under Discretion and Asymmetric Information." Econometrica 54 (5): 1099-1128. doi:10.2307/1912324.

Erkam, S. 2008. "Enflasyon ve Enflasyon Belirsizliği: Türkiye Örneği.” Sosyo Ekonomi 7 (7): 157-175.

Evans, M. 1991. "Discovering the Link Between Inflation Rates and Inflation Uncertainty." Journal of Money, Credit, and Banking 23: 169-184. doi:10.2307/1992775.

Fountas, S., A. Ioannidi, and M. Karanasos. 2004. "Inflation, Inflation-Uncertainty, and A Common European Monetary Policy." Manchester School 72 (2): 221-242. doi:10.1111/ manc.2004.72.issue-2.

Grier, K. B., and M. J. Perry. 1998. "On Inflation and Inflation Uncertainty in the G7 Countries." Journal of

\section{Appendix}

This appendix presents the data that we apply to evaluate the time-varying effect of inflation uncertainty on inflation. For the analyses, we use the monthly consumer price index (CPI) and its five subcomponents: (i) clothing and footwear; (ii) furnishings, household equipment, routine maintenance of house, (iii) health services, (iv) trans-
International Money and Finance 17 (4): 671-689. doi:10.1016/S0261-5606(98)00023-0.

Holland, A. S. 1995. "Inflation and Uncertainty: Tests for Temporal Ordering." Journal of Money, Credit and Banking 27 (3): 827-837. doi:10.2307/2077753.

Koopman, S. J., and E. Hol Uspensky. 2002. "The Stochastic Volatility in Mean Model: Empirical Evidence from International Stock Markets." Journal of Applied Econometrics 17 (6): 667-689. doi:10.1002/(ISSN)1099. 1255.

Nas, T. F., and M. J. Perry. 2000. "Inflation, Inflation Uncertainty and Monetary Policy in Turkey: 1960-1998." Contemporary Economic Policy 18: 170-180.

Stock, J. H., and M. W. Watson. 2007. "Why Has U.S. Inflation Become Harder to Forecast?" Journal of Money, Credit and Banking 39: 3-33. doi:10.1111/jmcb.2007.39. issue-s1.

Table A1. Data description.

\begin{tabular}{|c|c|}
\hline Inflation type & Definition \\
\hline Consumer price index (CPI) & $\begin{array}{l}\text { CPI is the General Consumer Price Index based on } 2003=100 \text {, which is a combination of two series: TP.FG. } \\
\text { F01 } 1982 / 01-2002 / 12(1987=100) \text { and TP.FG.J0 } 2003 / 01-2016 / 04(2003=100)\end{array}$ \\
\hline Clothing and footwear & $\begin{array}{l}\text { This is is based on } 2003=100 \text { and is obtained from TP.FG.T06 } 1982 / 01-2002 / 12(1987=100) \text { and TP.FG. } \\
\text { J03: } 032003 / 01-2016 / 04(2003=100)\end{array}$ \\
\hline $\begin{array}{l}\text { Furnishings, household equipment, routine } \\
\text { maintenance of house }\end{array}$ & $\begin{array}{l}\text { This is based on } 2003=100 \text { and is obtained from TP.FG.T14: } 51982 / 01-2002 / 12(1987=100) \text { and P.FG. } \\
\text { J05 } 2003 / 01-2016 / 04(2003=100)\end{array}$ \\
\hline Health services & $\begin{array}{l}\text { This is based on } 2003=100 \text { and is obtained from TP.FG.T21 1982/01-2002/12 }(1987=100) \text { and TP.FG.J06 } \\
2003 / 01-2016 / 04(2003=100)\end{array}$ \\
\hline Transportation services & $\begin{array}{l}\text { This is based on } 2003=100 \text { and is obtained from TP.FG.T25: } 71982 / 01-2002 / 12(1987=100) \text { and TP.FG. } \\
\text { J07: } 07.2003 / 01-2016 / 04(2003=100)\end{array}$ \\
\hline Recreational and cultural services & $\begin{array}{l}\text { This is based on } 2003=100 \text { and is obtained from TP.FG.T29 1982/01-2002/12 }(1987=100) \text { and TP.FG.J09 } \\
092003 / 01-2016 / 04(2003=100)\end{array}$ \\
\hline
\end{tabular}

portation services and (v) recreational and cultural services. They are a combination of two series that belong to the periods $1982 / 2001-2002 / 2012(1987=100)$ and $2003 / 2001-2016 / 2004(2003=100)$. Because the classification method changed in 2003, only five of the CPI components are suitable for the entire sample period that we consider. 